\title{
Is there a Spirit of Overseas Chinese Capitalism?
}

\author{
Swee Hoon Chuah • Robert Hoffmann • \\ Bala Ramasamy $\cdot$ Jonathan H. W. Tan
}

Accepted: 19 May 2016/Published online: 4 June 2016

(C) The Author(s) 2016. This article is published with open access at Springerlink.com

\begin{abstract}
The economic miracle of the Chinese Diaspora in Southeast Asia has been attributed to their unique economic culture forged from Confucian thought and the emigration experience. However, this Spirit of Overseas Chinese Capitalism (SOCC) hypothesis, based largely on qualitative research, has not been validated through quantitative work. This paper provides, for the first time, empirical evidence from a values survey and experiment which show that only some of the hypothesised SOCC values and behaviours differentiate the Chinese from less economically successful ethnic groups in Malaysia. While we find no evidence that Confucian values explain the success of the Overseas Chinese we do find it may lie in their (a) more conductive work values and (b) greater intra-ethnic cooperativeness, both accentuated by the emigration experience.
\end{abstract}

Authors appear in alphabetical order.

S. H. Chuah · R. Hoffmann $(\bowtie)$

Behavioural Business Lab, School of Economics, Finance and Marketing, RMIT University, Melbourne, VIC, Australia

e-mail: robert.hoffmann@rmit.edu.au

B. Ramasamy

China Europe International Business School, Shanghai, People's Republic of China

J. H. W. Tan

Centre for Research in the Behavioural Sciences,

Nottingham University Business School, Nottingham, UK
Keywords Chinese Diaspora - Cultural values . Family businesses · Enterprise - Questionnaire . Experiment

JEL Classifications $\mathrm{C} 72 \cdot \mathrm{C} 91 \cdot \mathrm{F} 22 \cdot \mathrm{L} 26 \cdot$ Z13

The hotel's owner and all the employees were Chinese. The only Malay was the doorman who carried the luggage of the guests who were also Chinese. After about two words of conversation, he too started telling about the problem that divides Malaysia: race. 'Look,' he said with a sweeping wave of the hand. 'The skyscrapers are Chinese, the market stalls are Chinese, the shops are Chinese, the supermarkets are Chinese... So tell me: is this Malaysia?' Just then a motorcycle with a sidecar pulled up in front of the hotel. The rider took his helmet off and set to work. In the space of a few minutes he had turned the sidecar into a miniature restaurant [...] The man was Chinese. Chinese were all the people I saw in the streets, busily running here and there with all sorts of errands. With such competition the poor Malay felt he would never get anywhere.

Tiziano Terzani, A Fortune Teller Told Me: Earthbound Travels in the Far East 


\section{Introduction}

Political and economic turmoil in early twentieth century China produced waves of emigrants who quietly built something of an overseas Chinese Wirtschaftswunder in the countries they settled in. The Chinese Diaspora in Southeast Asia "constitutes one of the world's wealthiest, most technically sophisticated and highly entrepreneurial groups" (Kotkin 1992, p. 8). They are a "poorly understood economic power $[\ldots]$ responsible in large part for the entire region's unparalleled economic success" (Weidenbaum and Hughes 1996, p. 8). Ethnic Chinese make up less than $5 \%$ of Southeast Asia's 600-million population but contribute many times their share to the regional economy. According to a range of indicators (such as ownership of private domestic firms and capital, total sales, business taxes or corporate investments), ethnically Chinese control between one and three quarters of private business activity in Southeast Asia. ${ }^{1}$ Their combined GDP measured two-thirds of Mainland China's towards the end of the twentieth century (Redding 1990, p. 3). The Chinese in Southeast Asia not only dominate the economies of their adopted countries dramatically but also constitute a major source of FDI-led growth in Asia generally and Mainland China in particular (e.g. Rauch and Trindade 2002; Tong 2005; Huang et al. 2013). The rise of the Chinese Diaspora economy in Southeast Asia has significance for the global economy as well as implications for different aspects of business practice in the region.

A great deal of research has tried to pinpoint the sources of the Chinese Diaspora economic miracle in Southeast Asia. One set of explanations in the tradition of Max Weber's Protestant Work Ethic attributes it to a distinct economic culture forged from the specific traditions and history of the Overseas Chinese. This culture is associated with particular efficacious values and behaviour patterns that allow the Overseas

\footnotetext{
1 Accurate measurement is fraud with practical difficulties due to unreliable records of the (opaque) business activities and population share of the Chinese Diaspora in their host nations. For estimations see Redding (1990, pp. 3; 24-33; 57), Kotkin (1992, pp. 179-180), Weidenbaum and Hughes (1996, pp. 8; 24-27), Kao (1993, pp. 24; 32), Tanzer (1994, pp. 138-139), Sowell (1996, p. 176), Koon (1997, p. 155), Westwood (1997, pp. 447-448), Chua (2004, pp. 23-48), Lee (2006) and Redding and Witt (2008, p. 66).
}

Chinese and their businesses to flourish. The bestknown and most comprehensive formulation of this is Redding's (1990) Spirit of Overseas Chinese capitalism (SOCC). It posits (1) specific, identifiable values and behaviours that (2) define the Overseas Chinese, (3) delineate them from other cultural groups in Southeast Asia and (4) can be traced in their development (Redding 1990, pp. 11-12).

To some, the SOCC and similar cultural theories provide cogent or at least intuitively appealing accounts of the Overseas Chinese economic success (see Tu 1989; Fukuyama 1993; Powell 1993). Others have dismissed them as little more than cliché derived from anecdotes (see Studwell 2007; Gomez 2007a; Bremner 2007). One type of criticism applies to cultural theories generally. While cultural factors can enrich economic theories (Guiso et al. 2009), they can also lead to tautologous, all-encompassing explanations that often fail to specify causal mechanisms from particular values to economic performance (Fukuyama 1993; Wong 1996; Frederking 2002; Yin 2003). A second criticism is that the Chinese Diaspora is culturally more diverse than the SOCC suggests. Accounts like the SOCC implicitly assume a degree of cultural homogeneity of the Overseas Chinese who arrived in Southeast Asia from different ethnic and geographic backgrounds in different historical contexts and for different reasons (see McKeown 1999; Chan 2015). In addition, the Chinese Diaspora culture may be subject to significant intergenerational change (King 1996; Gomez 2007a; Po 2010; Koning and Verver 2013), yet their economic superiority remains. Finally, specific components of the SOCC have also been disputed, as will be discussed later.

The debate over cultural explanations of Chinese Diaspora success is largely an empirical question (Wong 1996) that can be resolved to the extent that better measurements and data sources for Overseas Chinese culture become available. Following the seminal work of Hofstede (1984) and Inglehart (1997), cultures can be measured in terms of the extent to which their members exhibit particular attitudes and values (Chuah et al. 2009, p. 735). In contrast to these survey-based cultural frameworks, Redding's SOCC is based on extensive interviews, anecdotes and raw statistics which "renders his argument in want of further investigation" (Yin 2003). The same is true for other well-known contributions in the same vein, such as Sowell's (1996) 
Migrations and Cultures, Kotkin's (1992) Tribes and Weidenbaum and Hughes's (1996) Bamboo Networks (see Powell 1993; Tanzer 1994; Stapleton 1997; Kotkin 2010). In line with their intended audience, the latter two books especially were influential in policy and business rather than academic research circles.

The generality of qualitative work can be examined using quantitative approaches such as questionnaire surveys or experiments (Johnson and Onwuegbuzie 2004). However, to date there are no studies that quantitatively examine the existence of SOCC values and behaviour patterns. In this paper, we aim to contribute to the discussion of entrepreneurial culture among the Overseas Chinese by providing for the first time empirical evidence for the SOCC in the context of Malaysia. The spectacular economic success of the Chinese in Malaysia compared to other cultural groups there is typical for Chinese Diaspora communities in Southeast Asia generally. We examine whether Chinese Malaysians generally possess the particular cultural values and behaviour patterns proposed in the literature and whether, in this regard, they differ from other communities in Malaysia or Mainland China.

This work has been made possible by the first World Values Survey (WVS, see Inglehart 1997) conducted across Malaysia as well as data from an experiment we conducted in Malaysia with members of the different ethnic groups. Our approach is to adopt two established tools to measure cultural values and economic behaviour patterns. First, we use the WVS data to assess the relevant cultural values and attitudes of ethnic Chinese compared to these other ethnic groups. Second, we use experimental data that allows us to examine the behaviour of subjects from each of ethnic groups towards each other, while controlling for learning effects and ethnic differences in intrinsic cooperativeness. Chuah et al. (2014) analysed this dataset for the interplay of ethnic and religious discrimination at the aggregate level. In the present paper, we instead focus on testing SOCC hypotheses by comparing the Chinese and non-Chinese for behavioural differences in ethnic discrimination.

Entrepreneurship as a driver of economic growth is now well established (Audretsch et al. 2006). What determines the level of entrepreneurship in different countries is a critical question. Culture can act as an enabler or a barrier to entrepreneurship since values and norms prevalent in a society can influence the propensity of an individual starting a business (Etzioni 1987). Ethnicity and religion are important components of culture (Weber 1976). If ethnicity and religion have an important influence on entrepreneurship, then we have to conclude that some groups within a country will be more entrepreneurial than others since these cultural institutions are relatively fixed (ethnicity more than religion). Although ethnic Chinese in Southeast Asia and entrepreneurship are considered synonymous anecdotally, our study is important because it provides empirical evidence that questions such relationships. More specifically, we study if the enterprising spirit among the Chinese is a result of the values and norms embedded within the Confucian culture that they are part of or due to the immigrant nature of their society. Answers to these questions increase our knowledge to the link between culture and entrepreneurship.

Section 2 provides the background to the Overseas Chinese economic dominance in the specific context of Malaysia-our chosen location of study. In Sect. 3 we review the SOCC framework put forward in response to explain this phenomenon here and in other Chinese Diaspora nations. Our approach to testing the SOCC and the hypotheses involved are outlined in Sect. 4. Sections 5 and 6 describe the respective motivations, designs and results of the two empirical approaches. A discussion of our findings and conclusions are contained in Sect. 7.

\section{The Overseas Chinese in Malaysia}

Malaysia is a middle-income country in Southeast Asia with a per-capita GDP slightly less than half of that of the USA. ${ }^{2}$ Its multi-ethnic population of 30 million consists of three main groups, indigenous Malays (55\%), Chinese (24\%) and Indian Malaysians $(7 \%)$. Each is associated with its own traditional languages (Malay, Southern Chinese dialects and Tamil) and religions (Islam, Chinese Folk Religion and Hinduism), with English and Christianity common especially among urban and educated Malaysians. ${ }^{3}$ The economic power of the ethnic Chinese is a

\footnotetext{
${ }^{2}$ Estimated at 25,100 US Dollars in 2014. Source: CIA World Factbook.

${ }^{3}$ Islam is the official religion of Malaysia assigned to all Malays at birth. Members of other religions are able to convert freely.
} 
constant backdrop to the nation's public discourse (e.g. Fontaine and Richardson 2003). In terms of its historical, demographic, economic, and political context, the Malaysian Chinese Diaspora phenomenon is typical of Southeast Asia generally.

Present-day Malaysian society is the product of British colonial labour import policies as well as the socio-economic uncertainty in Mainland China during the first half of the twentieth century. ${ }^{4}$ Chinese immigrants typically lacked opportunities for land ownership or public sector employment and embraced the private business sector as intermediaries between indigenous workers and colonial overlords. A division of labour along ethnic lines into Malay agriculture, Chinese commerce and Indian industrial manual labour emerged. The resulting economic disparities favouring the Chinese fuelled inter-ethnic tension resulting in sporadic open conflict after independence in 1957 (Kotkin 1992, pp. 181-182; Weidenbaum and Hughes 1996, p. 4, 25-26; Chua 2004, pp. 43-48). The ethnic Chinese therefore remained largely unassimilated (Weidenbaum and Hughes 1996, pp. 9-10) ${ }^{5}$ and preserved their ethnicity and cultural traditions through vernacular education, discouragement of intermarriage and maintenance of ties to the mainland (Kotkin 1992, pp. 169-173).

In order to promote greater integration and economic parity among the different ethnic groups, the fledging Malaysian state implemented the National Economic Policy (NEP). It consisted of legislation designed to raise company shareholdings and board membership towards the Malays as well as their standing in the public service and education spheres. While this wide-ranging and institutionalised positive discrimination eased ethnic conflict, it did little to reduce the economic disparity between the groups. An uneasy ethnic equilibrium of a Malay political monopoly and Chinese economic dominance was reached and continues to overshadow society to this

\footnotetext{
${ }^{4}$ Chinese Diaspora history is outlined in Freedman (1979a, pp. 3-21), Wang (1991), Kotkin (1992), Sowell (1996, pp. 190-197) and Weidenbaum and Hughes (1996) as well as Redding and Witt (2008, chapter 5).

5 This is also true in other immigration nations with culturally and ethnically different indigenous populations such as Indonesia and the Philippines. Other nations such as Thailand pursued active integration policies.
}

day (Gomez 2003; Verkuyten and Khan 2012). All Malaysian prime ministers have been Malay and their ethnic UMNO party has held power without interruption since independence. On the other hand, at the end of the twentieth century, ethnic Chinese owned $37.9 \%$ of the share capital in Malaysian limited companies, compared to Malay and Indian ownership of 19.1 and $1.5 \%$, respectively (Gomez 2003). Despite operating in somewhat disadvantageous conditions, Chinese equity doubled from 22.8 to $45.5 \%$ in the NEP years between 1969 and 1999 (Gomez 1999, 2003). In 2005, Chinese owned $71.9 \%$ of commercial property in Malaysia, a proxy for their disproportionate participation in the business sector compared with $11.7 \%$ Malay and $4.6 \%$ Indian ownership (Shafii et al. 2009). Similarly, the Malaysian business community especially at the managerial level does not reflect the national ethnic mix but is dominated by ethnic Chinese (Bhopal and Rowley 2005 , p. 563). In 2002, the mean monthly gross income of Chinese households was 1.8 times greater than that of Malay and 1.4 of Indians households (Shafii et al. 2009). In 2012, the average monthly income for Chinese, Indian and Malay households was RM6366, 5233 and 4457, respectively (Khazanah Research Institute 2014). According to the Forbes Magazine 2013 Rich List, eight of the Top 10 richest Malaysians were Chinese. Of the ten biggest privately Malaysian-owned listed companies seven have Chinese majority shareholders. (Khazanah Research Institute 2014).

A great deal of research has tried to pinpoint the sources of this Chinese Diaspora economic miracle in Southeast Asia. As the anecdote at the beginning of the paper illustrates, its engine lies in the creation of Chinese small and medium- sized enterprises (SMEs) (Montesino 2012, p. 123) which play a large role in the Malaysian economy (Gomez 2012, p. 54) and its economic history as an international trade centre (Ariff and Lim 2001; Ariff and Syarisa Yanti 2002). While large foreign firms dominated the Malaysian economy during colonial times, ethnic Chinese entrepreneurs since built and dominated a growing SME sector (Gomez 2012; Minai et al. 2012). These ethnic Chinese enterprises typically remained familyowned and controlled as they underwent growth (Jesudason 1997) facilitated by ethnic Chinese business networking and guanxi (Minai et al. 2012; Julian and Ahmed 2012). In contrast, the indigenous Malay 
proportion of SMEs declined despite government affirmative action programmes designed to promote them (Gomez 2012).

The reasons for the economic success of the Chinese Diaspora in Southeast Asia therefore reside in their entrepreneurship and creation of small enterprises. Ethnic differences in entrepreneurial proclivity have been identified between the ethnic Chinese, Malays and Indians in Malaysia (Xavier et al. 2010). This reflects empirical evidence from elsewhere that entrepreneurship activity differs between as well as within countries along ethnic lines (e.g. Basu 1998; Fairlie 2004; Clark and Drinkwater 2008). These differences have been attributed to a mixture of "push" (threat) and "pull" (opportunity) factors promoting entrepreneurial activities (Constant and Zimmermann 2006; Clark and Drinkwater 2008; Basu 1998; Uhlaner and Thurik 2007). The push factors include the economic or institutional environment (e.g. Robson 2007), which may affect different ethnic groups differently (De Clercq et al. 2013), for example in the presence of ethnic discrimination or affirmative action as practiced in countries like Malaysia (Rasiah 2002). Among the pull factors are favourable, culturally transmitted entrepreneurial values (Wyrwich 2015), strategies (Bhalla et al. 2007) or trading opportunities (Wang and Liu 2014) that differ between ethnic groups. A number of studies in this area examine the particular cultural values that generate push and pull effects on entrepreneurship. Zelekha et al. (2013) found that religious values, through national culture, affect entrepreneurial activity at the country level. Wennekers et al. (2007) reported a positive association between uncertainty avoidance (Hofstede 1984, see) and business ownership rates in OECD countries. The interpretation is that a restrictive organisational culture pushes some people into starting their own businesses. Using the WVS, Uhlaner and Thurik (2007) find that cross-country entrepreneurial activity is negatively related to post-materialist values (Inglehart 1997). In another WVS-based study, Suddle et al. (2010) also use certain items to derive an individual values-based indicator of entrepreneurship that explains nascent entrepreneurship rates across 34 countries. Cultural studies to immigrant entrepreneurship therefore present a promising avenue to explain the economic success of the Overseas Chinese in Southeast Asia.

\section{The Spirit of Overseas Chinese Capitalism}

Cultural approaches to explain macroeconomic performance have recently enjoyed resurgence in economics (e.g. Guiso et al. 2006, 2009). Similarly, at the microeconomic level, cultural dimensions including religion, values such as post materialism (Inglehart 1997) and uncertainty avoidance (Hofstede 1984) and family values have been used to explain individual economic outcomes such as entrepreneurial activity and business ownership (e.g. Uhlaner and Thurik 2007; Bhalla et al. 2007; Wennekers et al. 2007; Zelekha et al. 2013; Wyrwich 2015). A number of writers have adopted the cultural approach to explain the Chinese Diaspora economic miracle through specific managerial practices and business behaviour of Chinese entrepreneurs, shaped by their distinct underlying economic culture. We henceforth refer to these explanations collectively as the SOCC (see Fig. 1).

The economic success of the Chinese Diaspora is based on particular business practices that have created "sub-economies" (Kotkin 1992, p. 172) in individual immigration nations which, across borders, constitute a "natural economic territory" (Weidenbaum and Hughes 1996, p. 8). These practices entail a distinct organisational form (Redding 1990, p. 3, 42) and leadership model (Westwood 1997) of the Diaspora Chinese enterprise and have been called a new economic system (Kotkin 1992, p. 186; Weidenbaum

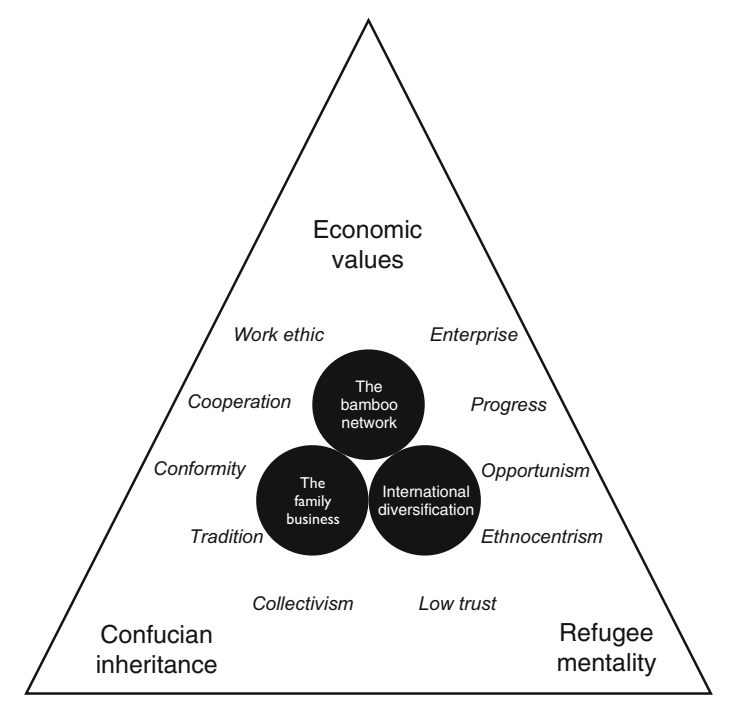

Fig. 1 The Spirit of Overseas Chinese Capitalism 
and Hughes 1996, pp. 52-53). Its basis is the familyowned and family-run business. Patriarchs typically govern it informally in a centralised, autocratic manner based on trust and interpersonal ties catering to a need for flexibility and control in weak and unpredictable legal environments (see Kotkin 1992, pp. 188-190; Weidenbaum and Hughes 1996, pp. 9-11, 29-30, 54-55). Key managerial roles are filled on the basis of family ties rather than merit. Diaspora Chinese family businesses remain typically small in size and eschew brand building or publicity in favour of trade, investment or intermediate goods manufacturing (Redding 1990, pp. 4-5; Kao 1993, p. 25; Weidenbaum and Hughes 1996, pp. 11, 29, 30, 54-55; Koon 1997, pp. 166, 175). Their operations are diversified across regions and industries and conducted opaquely across borders with multiple headquarters to minimise state oversight and permit hedging against political risks in individual nations (Kotkin 1992, pp. 179, 183). These Diaspora businesses are connected across Southeast Asia in decentralised "bamboo networks" based on clan ties or shared cultural identity. They function as arbitrage and mutual help networks and circulate knowledge, investment capital freely across national borders (Redding 1990, p. 67; Kotkin 1992, pp. 167-170, 186-188; Weidenbaum and Hughes 1996, p. 4, 26, 53; Koon 1997, p. 174). ${ }^{6}$ Bamboo networks operate informally on the basis of mutual trust and complex personal obligation substituting formal legal contracting. They are responsible for the economic success of the overseas Chinese in particular and Southeast Asia generally (Kotkin 1992, p. 8; Weidenbaum and Hughes 1996, p. 169).

According to the SOCC framework, these efficacious business practices of the Overseas Chinese were shaped by a distinct economic culture this group forged. Cultural innovation and change were necessary for the survival of the immigrants (Kao 1993). The traditional Chinese heritage of folk mores and Confucian thought was therefore merged with a "refugee mentality" that arose from the immigrant experience and exposure to Western culture in the colonised settlement nations (Godley 1981; Redding 1990; King 1996). Existing Confucian values were

\footnotetext{
${ }^{6}$ Rauch and Trindade (2002) show that bilateral trade between two nations is positively associated with the size of their respective Chinese minorities.
}

selectively retained or adapted in response to the needs of the uncertain and insecure environment within Southeast Asia (e.g. Kotkin 1992; Kao 1993). Godley (1981, pp. 33-35) argues that the economic success of Chinese immigrants in South-East Asia was partly dependent on jettisoning certain parts of the traditional Confucian culture such as the rejection of commerce and wealth accumulation as well as on adopting Western language and education. This "rationalistic traditionalism" (King 1996, p. 270) harbours a tension between a Confucian emphasis on tradition on one hand and the embracement of modern ideas on the other and created "a new kind of Chinese" with an "amazing willingness to split their personalities" (Godley 1981, p. 49) and a "remarkable ability to move in and out of the two traditions" (King 1996, p. 274).

\section{Hypotheses}

According to the SOCC, the economic success of the Overseas Chinese is the result of efficacious business practices that stem from their distinct economic culture forged from traditional values and the diaspora experience. Figure 1 sketches the SOCC framework in the relationships between the values of Overseas Chinese culture (in italics) and forms of business activity (shaded circles). For Redding (1990, p. 12), an identifiable group of such values exist which define members of the Overseas Chinese community. Further, these values differentiate the Overseas Chinese from other ethnic groups in Southeast Asia as well as from traditional Chinese culture (see also Godley 1981, chapter 2; Kotkin 1992, pp. 175-186; King 1996). In sum,

the understanding of Chinese capitalism [...] begins with an assumption that there is a distinct and bounded phenomenon to be explained [...] Overseas Chinese businessmen think sufficiently alike, and differently from others [such that they] have an apparently distinct economic culture, that it is describable, and the outline of its determinants can be drawn (1990, p. 12).

The purpose of the present paper is to provide a test of the SOCC using a quantitative approach. We measure the values and behaviours postulated by SOCC in the Malaysian Chinese Diaspora community 
and compare these to other Malaysian ethnic groups as well as Mainland Chinese. The SOCC is supported as an explanation of the economic success of the Diaspora Chinese to the extent that its members exhibit the postulated values more so than these other groups who did not experience such success. Conversely, if another Malaysian ethnic group with rather different economic fortunes is similar to the Chinese Diaspora in these values, then they fail to serve as an explanation. In the following we outline the specific values along with the SOCC hypotheses we derive from them.

\subsection{The Confucian inheritance}

The first aspect of the SOCC value system is traditional Confucian thought the Overseas Chinese inherited (bottom left corner in Fig. 1). Confucian values have previously been used to explain the economic success of Japan and the East Asian Tiger economies (e.g. Reischauer 1974; Kahn 1979; Pye 1985; Tu 1989). A number of authors make a similar case for the Diaspora Chinese in Southeast Asia (e.g. Freedman 1979b; Redding 1990; Kao 1993; Redding 1996; Koon 1997; Westwood 1997). Different dimensions of Confucianism have been identified (for overviews of traditional Chinese values see Hofstede and Bond 1988; Redding 1990; Kao 1993).

\subsubsection{Attitudes}

The first is respect for tradition. Chinese culture endures historically because preservation is one of its core values (Bond 1988, p. 1010) supported by childhood socialisation (Wu 1996). Empirical studies have shown this traditionalism to be a core value of Chinese culture generally (Bond et al. 1987; Chan and Rossiter 1998) and of Overseas Chinese culture specifically (Wu 1996). Likewise, after their exodus from the mainland, generations of Diaspora Chinese deliberately preserved their traditional Chinese cultural identity and heritage through the establishment of Chinese Schools (Freedman 1979a, p. 10) and the promotion of the Chinese language (Redding 1990, p. 58; Kotkin 1992, p. 173) and Confucian values (Redding 1990, p. 48; Weidenbaum and Hughes 1996, p. 28) in their foreign-born offspring who were exposed to alternative indigenous cultures. Cultural preservation was aided by the increasing influx of female immigrants from China that made these communities more sustainable (Freedman 1979a, p. 9; Wang 1991, p. 150). Empirical support is provided by $\mathrm{Wu}$ (1996), who found that Overseas Chinese parents in Singapore share the traditional Chinese belief in education and its importance in maintaining Chinese culture among them and of Confucian values in particular.

The second dimension of Confucian values is the attitude of conformity. Individual motivations are suppressed in favour of the group generally and the family in particular. The family order is sustained by the key value of filial piety, i.e. obedience towards parents and seniors according to a strict hierarchy based on age and gender which is sometimes harshly enforced. Filial piety is also extended to other power relationships in the workplace and civil sphere. The acceptance of hierarchical vertical relations that secure social order is therefore a key component of Chinese culture (Redding 1990, pp. 45-61; Weidenbaum and Hughes 1996, p. 28; 54). The authority of seniors is not to be challenged by loyal, passive and deferent subordinates. In return, the former have a duty of care towards those under their control and are expected to exercise their power wisely, righteously and compassionately, which serves as a source of their perceived legitimacy.

The third dimension is collectivist support of others. Here, horizontal relationships are only secondary to vertical ones. The individual is seen as a node in a social network of mutual obligations and investment. Personal interests are subsumed under the whole, the harmony of which is pursued. The individual is therefore sensitised towards the opinions of others who are a source of face or good standing in the community, or conversely shame, which constitutes the chief social compliance mechanism. Behaviour towards peers should be helping and human hearted (Redding 1990, p. 49). There is an acceptance of collective responsibility over communal assets (Kotkin 1992, p. 188; Weidenbaum and Hughes 1996, p. 28, 54).

Confucianism forms a set of connected "Asian values" (Barr 2000) held in different Asian societies to different degrees (Storz 1999) and has been used to explain the economic performance of some of them (Reischauer 1974; Kahn 1979; Pye 1985). In the words of Tu $(1989$, p. 83), 
the basic ethical concepts and value systems of the four countries [China, Japan, Korea and Vietnam] are surprisingly uniform. For example, all show a strong emphasis on family solidarity, on filial piety, on subordination of the individual to the group, on the ideal of group harmony.

Similarly, the Confucian values of tradition, conformity and collectivism provide the foundation of the Overseas Chinese family business that has been identified as the engine of their economic success. In particular, Confucian values provide the governance mechanism that affords the family patriarch organisational control and flexibility at low transaction cost. To the extent that Confucian thought and the family business are particular to Chinese culture its values should differentiate the Overseas Chinese from other Malaysians.

Hypothesis 1a The Chinese have stronger Confucian values than members of other Malaysian ethnic groups.

\subsubsection{Behaviour}

Cooperation is a behavioural aspect of SOCC potentially driven by Confucian values. The SOCC framework attributes specific cooperative behaviour to the Overseas Chinese. Cooperative behaviour has been found to relate generally to collectivist values (Triandis 1989; Cox et al. 1991). This compels us to also seek behavioural evidence of SOCC in strategic interactions. For this, we define cooperation according to behaviour in the game theoretic parable of the prisoner's dilemma. It is a tractable and leading approach to modelling settings in which cooperation is of key concern. Indeed, the business relationships of the Overseas Chinese specifically have been likened to a prisoner's dilemma (Harianto 1996, p. 140). It is a mixed-motive game that pits self-interest against social concerns and allows a variety of economic and social values to express themselves. Here, decision makers (known as a "players") choose between cooperation and competition with interactive partners (known as a "co-players"). If players interact repeatedly, they must evaluate strategies by comparing the value from a sustained cooperative relationship versus that of competitive relationships. In parallel to business networks, the dyadic and repeated nature of this abstract strategic interaction (known as a "game") reveals how a player's cooperativeness is influenced by the cultural difference or similarity of the coplayer. It has been used to study interactions across ethnic groups within (e.g. Cox et al. 1991) or between nations (Hemesath 1994). We follow this approach in defining and measuring cooperation.

By the SOCC, cooperation as such is supported by collectivist ideals of mutual cooperation (Redding 1995, p. 179), which are enforced by informal community sanctions often more powerful than legal norms. Reverting from cooperation to non-cooperation constitutes a sanction in the prisoner's dilemma. In this way Confucian values provide social capital in a "moral base" for cooperation between individuals as well as organisations that allows economic development (Redding 1996). The result is a "heightened sense of cooperativeness within the Overseas Chinese group generally" which is the root of the greater economic success of the Chinese (Redding 1990, p. 34). Cooperation provides a distinct advantage that "converts an otherwise disparate group of entrepreneurs into a significant economy" (Redding 1995, p. 2; 62). The resulting Chinese "networks of cooperation" reduce transaction cost by supplanting formal agreements and legal enforcement (Weidenbaum and Hughes 1996, p. 53). In the words of Redding (1995, p. 2), "this is the feature which unites them, and which provides them with one of their most distinct strengths-a capacity to cooperate". As a result, we expect mutual cooperation among the Chinese to be greater than within other Malaysian ethnic groups.

Chinese Diaspora cooperativeness is not universal but directed preferentially towards others within the Chinese cultural group following the Confucian system of relationships (Redding 1990, p. 68). Conversely, cooperation with members of other groups and strangers generally is limited by mistrust (Redding 1990, p. 36). This is consistent with Triandis (1989) who proposed that in general, collectivists cooperate preferentially with in-group members. We therefore expect relatively less cooperation when Overseas Chinese interact with ethnic out-group members. Further, we expect Chinese to exhibit this discriminating behaviour more than members of other ethnic groups in Malaysia.

Cooperation based on the ethnic identity of others is a foundation of the "bamboo networks" among ethnically Chinese firms in Southeast Asia. It has provided a valuable mutual support network for 
finance, information and investment opportunities. Discrimination is the converse to the preferential treatment of culturally and ethnically similar people, which allowed the Overseas Chinese to cooperate among each other and form the bamboo networks essential to their economic success.

It is important to examine behaviour as well, because mere attitudes of the Overseas Chinese may not translate fully into the economic behaviour, which we are interested in (e.g. Ajzen 2012). Questionnaire responses may be subject to various biases (Bertrand and Mullainathan 2001; Chandon et al. 2005) especially when decision alternatives are not associated with corresponding financial consequences. In the experimental part of our study, we examine whether Malaysian Chinese subjects exhibit behavioural differences to those from other Malaysian ethnic groups in line with the SOCC. In particular, we examine the above-mentioned notions of cooperativeness and ingroup favouritism, i.e. greater cooperation generally and especially within networks of ethnically similar people.

The following hypothesis is derived from how the SOCC expects interactions among fellow Chinese to be more cooperative, and such discrimination is stronger than among members of other Malaysian ethnic groups.

Hypothesis 1b The Chinese cooperate more with each other than members of other Malaysian ethnic groups.

\subsection{The refugee mentality}

The second aspect of the SOCC is a set of new values that developed in response to the experience of exodus and immigration (bottom right corner in Fig. 1). The Overseas Chinese experienced difficult economic, social and political conditions in Southeast Asia, in particular fear of persecution and expropriation.

The first attitude relates to generalised trust in strangers (Fukuyama 1995), an important cultural value examined in a number of studies in economics (e.g. Glaeser et al. 2000; Zak and Knack 2001). The Diaspora experience has instilled low generalised trust in the Overseas Chinese. Uncertainty is met by an emphasis on self-reliance within the family unit rather than looking for support outside it (Kotkin 1992, p. 185). There is a low level of trust in strangers generally and in people from other ethnic groups as well as in state institutions specifically (Redding 1990, p. 66; Weidenbaum and Hughes 1996, p. 52, 54). Low trust serves the Overseas Chinese as a safeguard against exploitation and a motivation for international diversification. In addition, the converse of low trust is cooperation with and investment in those to whom ethnic links or mutual obligations exist. We therefore expect to find these values relatively more in Chinese Malaysians.

The conditions of uncertainty and distrust are accompanied by the second attitude: ethnocentrism (Weidenbaum and Hughes 1996, p. 52) sustained by a sense of cultural superiority (Redding 1990, p. 57) expressed in discriminatory attitudes towards people from other ethnic or language groups and religions which can translate into discriminatory behaviour (see Hypothesis 1b). Ethnocentrism may contribute to the economic success of the Overseas Chinese through preferential and effective interactions within the ethnic group supported by the development of cooperative social norms (Henrich and Henrich 2007). Again, the SOCC framework suggests this value to be more associated with Malaysian Chinese than the other groups.

In the economic literature on transaction cost, opportunism is defined as "self-interest seeking with guile" and "includes but is scarcely limited to more blatant forms, such as lying, stealing, and cheating" (Williamson 1985). It has been identified as a third value dimension of the refugee mentality involves pragmatism or situation orientation (see for example Chan and Rossiter 1998) and opportunism (Redding 1990, p. 3; Hong et al. 2010, p. 21, Wah 2001). The ability of the Overseas Chinese to adjust to uncertainty is partly shaped by their origins in the Southern Chinese working classes (Redding 1990, p. 71). The resulting pragmatic outlook unencumbered by abstract principles (Redding 1990, p. 62; 76) facilitates the adaptation of traditional values to better pursue economic motivations (King 1996, pp. 270-272). Short-term and competitive behaviour is accentuated in interactions characterised by low trust or social distance (Fang et al. 2008, p. 166). As a result, opportunism may be expressed in unprincipled behaviour for material gain. A pragmatic attitude has allowed the Chinese to adapt traditional values to thrive and seize opportunities in the capitalist environment (King 1996, p. 270-272). In these ways 
opportunism may support the economic success of the Chinese Diaspora. To this extent opportunist values should be relatively more pronounced in the ethnic Chinese.

The refugee mentality with the associated distrust in strangers and state institutions, ethnocentrism and opportunism forms the basis of the international diversification typical for Overseas Chinese businesses that contributes to their success. Diversification helps maintain low-profile operations and avoid taxes or other state interventions. Ethnocentrism channels business towards Chinese businesses in other nations rather than towards domestic ones owned by other ethnic groups. The following hypothesis is derived from how the SOCC expects Chinese to be less trusting of strangers and state institutions, and more ethnocentric and opportunistic than members of other Malaysian ethnic groups.

Hypothesis 2 The Chinese have a stronger refugee mentality than members of other Malaysian ethnic groups.

\subsection{Economic values}

The SOCC also entails a third group of values guiding economic and business behaviour, which arose as adaptations of existing Confucian values to the Diaspora experience (top corner in Fig. 1). To survive, traditional Chinese values were adapted and new ones emerged. Here are three economic values.

The first economic value is the hard work ethos of the Overseas Chinese, which arose naturally from traditional Confucian thought as well as the economic adversity of the diaspora experience (Harrell 1985). It involves a sense of responsibility, duty, seriousness about task, diligence and perseverance (Freedman 1979b, p. 22; Kao 1993, p. 25; Redding 1990, pp. 69-70; Weidenbaum and Hughes 1996, p. 28; Kotkin 1992, p. 172). Redding (1990, p. 70) notes that "the work ethic permeates Overseas Chinese life and, no matter its origins, be they family duty, acceptance of discipline, fear of insecurity, bred tolerance of repetition, or high-tuned pragmatism, its universality is sufficient to make it an expectations of those dealing with them." The work ethic is an important contributor to the success of Overseas Chinese businesses and is expected to be relatively more present in members of this group.
Second, the accumulation of wealth is the prime measure of achievement and social status and provides security (Redding 1990, pp. 70-72; Kotkin 1992, p. 171; 178-188; Kao 1993, p. 25; King 1996, pp. 268-271; Weidenbaum and Hughes 1996, p. 28, 54). While classical Chinese thought eschews gain for its own sake (Godley 1981; Lam 2003), a materialistic orientation of the Overseas Chinese has roots in Chinese folk culture (Freedman 1979b) reinforced by the diaspora experience as an insurance against adverse circumstances. Tung and Baumann (2009) identify a strong materialistic orientation in East Asian and Chinese culture generally and find evidence for this in Overseas Chinese in particular. Freedman (1979b) argues that the migrants' peasant background schooled them in the handling of money for lending and borrowing and financial dealings generally. The ethos is one of relying on oneself rather than on others or the state for material support (Kotkin 1992, p. 187; Redding 1990, pp. 69-70). Bargaining is seen as a virtue, as are frugality and the avoidance of ostentation, which may provoke envy from other groups. The resulting affirmation of competition and enterprise is similarly a response to environmental uncertainty and the opportunities it involves (Kotkin 1992, p. 167, 187; Kao 1993, pp. 27-34; Koon 1997, pp. 155-157; Weidenbaum and Hughes 1996, p. 27). This involves risk taking in lending, borrowing and investing the accumulated wealth to create new businesses. The internationally high proportion of savings among the Diaspora Chinese results from its perceived status as a source of business success and the importance of investment in particular. The success of Chinese Diaspora businesses may have roots in these entrepreneurial values. We therefore hypothesise the Overseas Chinese to exhibit these values to a greater extent than other groups there.

The third economic value is a belief in progress and modernisation. The diaspora experience of uncertainty and an endemic pragmatism led to an openness of the Overseas Chinese towards modern ideas that promoted economic success and ensured survival in a politically and economically adverse climate. The opportunity for modernisation was provided by exposure to novel Western ideas in colonial diaspora destinations. Here, the Overseas Chinese adopted elements of European culture, education, scientific advances and technologies 
(Kotkin 1992, pp. 177-178) more so than other cultural groups. Embracing progress enabled the Overseas Chinese entrepreneurs to flourish by adopting new products and production technologies. A belief in progress and modernisation should therefore distinguish the Malaysian Chinese from other Malaysian groups.

The following hypothesis is derived from how the SOCC expects Chinese to have a stronger work ethic and beliefs in private enterprise, progress and modernisation, than members of other Malaysian ethnic groups.

Hypothesis 3 The Chinese have stronger economic values than members of other Malaysian ethnic groups.

\section{Study A: values survey}

\subsection{Method}

In the first of the two studies, we use survey data for Malaysia to test the individual SOCC hypotheses stated above. In particular, we examine whether the Overseas Chinese in Malaysia display the individual hypothesised values and behaviours more compared with other ethnic groups here (i.e. Malays and Malaysian Indians) as well as Mainland China. We follow previous authors who used WVS data to examine the economic and business values of immigrant communities (e.g. Uhlaner and Thurik 2007; Suddle et al. 2010). The WVS is a periodic worldwide poll of socio-economic and political attitudes and values. The data we used are sourced from the 2005 (list A) wave (World Values Survey 2013). It covers a number of countries in Southeast Asia with Diaspora Chinese communities well as other Chinese societies such as Mainland China with sample sizes exceeding 1000 respondents for each. The WVS consists of a number of separate question clusters, respectively, designed to measure different value constructs including the SOCC ones we consider here. Our measures for the different hypothesised SOCC values were therefore generated by separate factor analyses of relevant such clusters as described below. In all these analyses, we performed Varimax rotation of the loadings matrix. Only items with factor loadings exceeding 0.5 and cross-loadings smaller than 0.4 were retained. All the resulting factors have item averages with eigenvalues exceeding 1.0 and satisfactory reliability in terms of Cronbach $\alpha>0.6$.

Table 1 shows the resulting factors we use as measures for different aspects of the SOCC. We calculated respondent scores for all the retained factors as the unweighted mean of all their respective items. Table 2 shows these averaged for the different cultural groups we are comparing. We use these to examine the extent to which Malaysian Chinese differ in their values from other Malaysian ethnic groups or Chinese societies elsewhere. In particular we performed the ANOVA within Malaysian society (i.e. between the three main ethnic groups). We report Scheffé post hoc test results for bivariate differences between Malaysian Chinese on the one hand and Malays or Indian Malaysians on the other. We also conducted $t$ tests for differences in mean scores between the Malaysian Chinese on the one hand and the Mainland Chinese on the other. ${ }^{7}$ In particular we use PRC respondents to measure values in traditional Chinese society.

\subsection{Results}

To measure Confucian values to test hypotheses 1a, 2 and 3, we follow Morris et al. (1998) as well as Böhm and Bergmann (2012) who use WVS items that make up the Schwartz (2001) Universal Human Values system for this purpose. A factor analysis of the ten WVS items constituting the Schwartz instrument generated a reliable five-item factor encompassing the key Confucian values tradition, conformity, security as well as support and responsibility for collective concerns. The former three constitute Schwartz's conservation dimension, while the latter two together make up self-transcendence in his system. We find that there are no significant differences in these Confucian values within Malaysia $(p=0.230)$. In particular, there are no significant differences between the Malaysian Chinese on the one hand, and Malays $(p=0.880)$ and Indians $(p=0.441)$ on the other. Interestingly, PRC Chinese are significantly less Confucian than Malaysian Chinese $(p=0.000)$. Traditional Chinese values have previously been found to

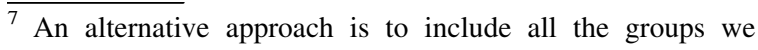
consider, i.e. those within and outside Malaysia, in a single ANOVA. In terms of significance of differences this approach generates the same results as the ones we report.
} 
Table 1 WVS questionnaire items for the retained factors

\section{Confucianism}

Important to this person (6: not at all like this person to 1 : very much like me)

Living in secure surroundings

To help the people

To always behave properly

Looking after environment

Tradition

Interpersonal trust

How much do you trust $(4=$ not at all to $1=$ completely) people

You meet for the first time

Of another religion

Of another nationality

Confidence in the state

How much confidence $(4=$ none at all, $1=$ a great deal $)$ do you have in

The police

The justice system

The government

Political parties

Parliament

The civil services

\section{Ethnocentrism}

Would not like to have as neighbours $(1=$ mentioned, $2=$ not mentioned $)$

People of a different race

People of a different religion

People who speak a different language

\section{Opportunism}

Is it justifiable to $(1=$ never justifiable to $10=$ always justifiable $)$

Claim government benefits to which one is not entitled

Avoid a fare on public transport

Cheat on taxes if one has a chance

Progress

Do you completely agree $(=10)$ or disagree $(=1)$ that

Science and technology are making our lives healthier, easier, and more comfortable

Because of science and technology, there will be more opportunities for the next generation

Science and technology do not make our way of life change too fast

Work ethic

Do you agree that $(1=$ strongly agree to $5=$ strongly disagree $)$

To fully develop your talents, you need to have a job

It is humiliating to receive money without working for it

People who don't work become lazy

Work is a duty towards society

Work should always come first, even if it means less free time 
Table 1 continued

\section{Enterprise}

Do you completely agree $(=1)$ or disagree $(=10)$ that

Private, rather than government, ownership of business and industry should be increased

People, rather than government, should take more responsibility to provide for themselves

Competition is good and stimulates people to work hard and develop new ideas

In the long run hard work usually brings a better life

Table 2 Average item and factor scores for Chinese (CHI), Indian (IND) and Malay (MAL) respondents in Malaysia as well as Chinese from the mainland (PRC) and Thailand plus Indonesia (THA)

\begin{tabular}{|c|c|c|c|c|c|c|c|c|c|}
\hline \multirow{2}{*}{$\begin{array}{l}\text { Group }(n) \\
\text { Value }\end{array}$} & \multicolumn{2}{|c|}{ MALAYSIA (1047) } & \multicolumn{2}{|c|}{ MAL (627) } & \multicolumn{2}{|c|}{ IND (109) } & \multirow{2}{*}{$\begin{array}{l}\text { CHI (311) } \\
\text { Score }\end{array}$} & \multicolumn{2}{|c|}{ PRC (2015) } \\
\hline & Score & ANOVA $p$ & Score & Scheffé $p$ & Score & Scheffé $p$ & & Score & $t$-test $p$ \\
\hline Confucianism & 2.74 & 0.230 & 2.71 & 0.880 & 2.85 & 0.441 & 2.74 & 2.57 & $0.000 * * *$ \\
\hline Cronbach $\alpha$ & 0.671 & & 0.682 & & 0.632 & & 0.661 & 0.678 & \\
\hline Interpersonal trust & 3.03 & 0.139 & 3.06 & 0.485 & 2.95 & 0.646 & 3.01 & 3.12 & $0.008 * * *$ \\
\hline Cronbach $\alpha$ & 0.741 & & 0.740 & & 0.718 & & 0.750 & 0.733 & \\
\hline Confidence in the state & 2.13 & $0.000 * * *$ & 2.09 & $0.001 * * *$ & 2.01 & $0.003 * * *$ & 2.24 & 1.81 & $0.000 * * *$ \\
\hline Cronbach $\alpha$ & 0.856 & & 0.838 & & 0.873 & & & 0.902 & \\
\hline Ethnocentrism & 1.78 & $0.002 * * *$ & 1.78 & 0.122 & 1.70 & $0.002 * * *$ & 1.83 & 1.84 & 0.338 \\
\hline Cronbach $\alpha$ & 0.742 & & 0.753 & & 0.675 & & 0.738 & 0.622 & \\
\hline Opportunism & 3.86 & 0.451 & 3.82 & 0.548 & 3.75 & 0.592 & 3.97 & 2.37 & $0.000 * * *$ \\
\hline Cronbach $\alpha$ & 0.796 & & 0.778 & & 0.823 & & 0.821 & 0.648 & \\
\hline Progress & 5.97 & 0.249 & 5.94 & 0.385 & 5.88 & 0.363 & 6.05 & 6.57 & $0.000 * * *$ \\
\hline Cronbach $\alpha$ & 0.858 & & 0.842 & & 0.869 & & 0.886 & 0.812 & \\
\hline Work ethic & 2.02 & $0.010 * *$ & 2.06 & $0.024 * *$ & 1.95 & 0.998 & 1.95 & 2.12 & $0.000 * * *$ \\
\hline Cronbach $\alpha$ & 0.640 & & 0.625 & & 0.745 & & 0.630 & 0.581 & \\
\hline Free enterprise & 5.03 & $0.001 * * *$ & 5.13 & $0.001 * * *$ & 5.05 & 0.237 & 4.82 & 4.84 & 0.886 \\
\hline Cronbach $\alpha$ & 0.636 & & 0.637 & & 0.583 & & 0.645 & 0.296 & \\
\hline
\end{tabular}

ANOVA $p$ values are for Malaysia as a whole. Scheffé post hoc $p$ values are for tests between Malaysian Chinese and Malays as well as Indian Malaysians. T-test $p$ values are for differences between CHI on one hand and PRC, TAI and THA respectively

Significance indicated at the $5(* *)$ and $1(* *) \%$-levels

be stronger in the Chinese Diaspora communities compared to the mainland (e.g. Wu 1996). The Cultural Revolution experience in this country may be a factor. Confucian values per se do not explain the relative economic success of the Overseas Chinese in Malaysia to the extent that other, less successful cultural groups possess these to the same extent.

Result 1a The Chinese do not have stronger Confucian values than members of other Malaysian ethnic groups.

We factor analysed a cluster of six WVS items designed to measure inter- personal trust and retained a single reliable factor consisting of three items relating to trust towards strangers. Another factor concerning trust in friends and family does not relate to our hypotheses and was not used in the analysis. The interpersonal trust measure is not different between the Malaysian Chinese and the other ethnic groups in Malaysia. However, the Malaysian Chinese trust significantly less than Mainland Chinese $(p=0.008)$, perhaps due to the former group's experience of ethnic conflict and immigration.

Confidence in the state is a single factor of six items obtained from the factor analysis of the twelve-item WVS cluster measuring trust in (private or public) organisations. All these items pertain to state institutions. Another factor relating to trust in private and 
non-governmental organisations was again not considered further as not being relevant to the SOCC hypotheses. The Malaysian Chinese as a group are significantly less confident in state institutions than other ethnic groups in the country and the Mainland Chinese $(p \leq 0.003)$. These findings reflect the refugee mentality of Chinese Diaspora communities, which in this dimension is, however, not shared by the Indian immigrant community in Malaysia.

Ethnocentrism is a single three-item factor that emerged from the factor analysis of a cluster of ten WVS items measuring attitudes to particular social groups. All three relate to attitudes towards other ethnic groups. The remaining factors and their items relate to social groups not based on ethnicity and were not analysed further as not relevant to the SOCC hypotheses. Compared with the other groups in the sample, we find that the Malaysian Chinese are significantly different (at or below the $5 \%$ level) to only Indian Malaysians in this regard, who are more ethnocentric according to this measure.

Result 2 The Chinese have a stronger refugee mentality in terms of less confidence in state institutions than members of other Malaysian ethnic groups.

The opportunism factor comprises three items from the factor analysis of a cluster of eleven items concerning the extent to which certain behaviours are acceptable. All three relate to cheating for personal material gain. The seven remaining items relate to other kinds of cheating not directly relevant to the SOCC hypotheses. There are no differences between Malaysian Chinese and all other groups except the Mainland Chinese, who self-report to be significantly less opportunistic.

Progress is measured as a single factor consisting of all four items in a cluster regarding attitudes towards science and technology. Again, the progress measures are generally not significantly different between the Chinese and other ethnic groups in Malaysia. However, PRC Chinese report significantly greater proprogress values.

The WVS also includes a five-item work ethic cluster from which we obtained a single reliable factor comprising all of them. The Malaysian Chinese report significantly greater pro-work ethic than all other groups bar Malaysian Indians.

Finally, there is a WVS cluster of six items relating to competition and private enterprise from which we obtained a single four-item factor. The remaining two items loaded on a separate factor with insufficient reliability, which we discarded. The Malaysian Chinese believe more strongly in free enterprise than members from the Malay majority, although there are no significant differences to Malaysian Indians who share their immigrant status.

Result 3 The Chinese have stronger economic values in terms of work ethic and beliefs in private enterprise than members of other Malaysian ethnic groups.

\section{Study B: behavioural experiment}

\subsection{Method}

To test hypothesis $1 b$, we analyse data from an experiment where behaviour is observed under incentive compatibility, i.e. where decision alternatives are associated with different monetary rewards. The experimental task was a pairwise 10-round prisoner's dilemma game where two players decide repeatedly and simultaneously between cooperation and defection. Following Andreoni and Miller (1993), we used payoffs of 7 for mutual cooperation, 4 for mutual defection, 0 for unilateral cooperation and 12 for unilateral defection. The game was presented in abstract form showing payoffs and actions labelled neutrally as A and B. While mutual defection in every round is the unique Nash equilibrium, experimental subjects typically cooperate to some extent especially in early rounds. Chuah et al. (2014) used this dataset to show that ethnic-based and religion-based biases coexist at the aggregate level and show that ethnic effects are robust to religious ones at the aggregate level. We are therefore able to further scrutinise biases specific to each ethnic group and compare them across groups without controlling for religion.

We conducted eight experimental sessions at a private, English-based university in Malaysia with 96 undergraduate subjects, i.e. 12 per session. Of these, $54 \%$ were of Chinese, $14 \%$ of Indian, $13 \%$ of Malay and $11 \%$ of other ethnic background. While our subject pool differs in the representation of the different ethnic groups from the general population, it is similar to the Malaysian business community generally and managerial or professional occupations 
in particular, which are dominated by the ethnic Chinese (Bhopal and Rowley 2005, p. 563). The average age of subjects was 21 years and $55 \%$ were male.

Subjects were randomly seated at partitioned terminals in a computer laboratory to ensure anonymity and privacy of decisions and provided with written instructions in English as well as a comprehension quiz. ${ }^{8}$ Subjects played a total of 11 games, one with every other subject present at the session. The games were played under three conditions. First, for every game, the co-player's ethnicity was either disclosed $(\mathrm{INFO}=1)$ or not $(\mathrm{INFO}=0)$. Further, when information was given, the co-player was either of the same $(\mathrm{SAME}=1)$ or a different $(\mathrm{SAME}=0)$ ethnic group. We provided additional co-player information, such as age as distractors to avoid bias from subjects' awareness of our research motivation. At the end of a typical 90-min session, one of the 11 games was selected at random for each subject who then received 0.40 Malaysian Ringgit (USD 0.13) in cash for each payoff point received over the 10 rounds plus a participation fee of Ringgit 10. On average, each subject received around 20 Ringgit, roughly USD 6.5 and more than equivalent to a typical subject's opportunity cost of participation.

\subsection{Results}

Cooperation is measured as the percentage of subjects who decide to cooperate rather than defect. The curves in Fig. 2 show cooperation by subject ethnic group for each of the ten rounds of games and for each of the three conditions (known same or different co-player ethnicity and no information). In line with previous experiments, subjects' higher early-round cooperation tails off over the course of a game with low cooperation in the final round. Table 3 displays average, first-round and final-round cooperation by player ethnic group and experimental condition. Strikingly, Chinese subjects generally seem to cooperate more than any other ethnic group overall $(39.9 \%)$, in the first and final round of games in all information conditions. The overall cooperation rate for Malay subjects, the majority ethnic group, is only around half as large $(19.0 \%)$. Indian subjects, the

\footnotetext{
${ }^{8}$ Experimental materials are available upon request to the corresponding author.
}

other immigrant group cooperate at levels similar to the Chinese (33.9\% overall). Relatively high cooperation within the Overseas Chinese community is a key aspect of the SOCC. Another is relatively high discrimination, defined as higher cooperation with members of the same ethnic group. We use our experimental data to test Hypothesis $1 \mathrm{~b}$.

Chinese cooperate more among themselves (43.9\% over all rounds) than Malays $(16.5 \%)$ or Indians $(34.3 \%)$. These differences are significant $\left(\chi^{2}-p=0.000\right)$ supporting Hypothesis $1 \mathrm{~b}$. Turning to the effect of the co-players (same or different) ethnicity on cooperation, Fig. 2 suggests that cooperation of each of the ethnic groups is highest when coplayers are known to be of the same ethnicity (light grey lines), followed by games with unidentified (black) and finally known ethnically different coplayers (dark grey). For the Malaysian Chinese (centre panel), these differences are significant. Their cooperation is significantly greater with identified Chinese than with non-Chinese co-players over all rounds (2tail Wilcoxon $p=0.023$ ) and in round 10 $(p=0.006)$. In contrast, similar tests suggest the overall cooperation of Malays and Indians is not significantly affected by identification, similarity or difference of the co-player. Overall these results suggest greater in-group favouritism by the Chinese (Hypothesis 1b). We also tested for these effects in a multivariate framework controlling for other relevant factors (see Table 4). In particular, we conducted Logit regressions on decisions coded as $0=$ defection and $1=$ cooperation. As every subject played in multiple games and rounds, we used a panel-data approach with random effects at the level of the subject. We treat Chinese subjects in the no information condition as the benchmark group. To test for the effects of known co-player ethnicity, we use INFO as well as an interaction term of INFO with SAME as independent variables. ${ }^{9}$ We also use dummy variables for subjects from other ethnic groups (MALAY and INDIAN). Finally, we control for subjects' learning effects over their 11 separate games (GAME) and ten rounds of individual games (ROUND). We find that for all subjects over all rounds of all games, these controls are significant. While cooperation falls over

\footnotetext{
${ }^{9}$ Our results are robust with regard to alternative specifications, such as entering INFO with INFO $\times$ DIFF, or INFO $\times$ SAME with INFO $\times$ DIFF.
} 
Fig. 2 Cooperation over rounds by subject ethnic group and experimental conditions of no information about co-player

(INFO $=0$ ), information about co-player's same $(\mathrm{SAME}=1)$ and different $(\mathrm{SAME}=0)$ ethnicity
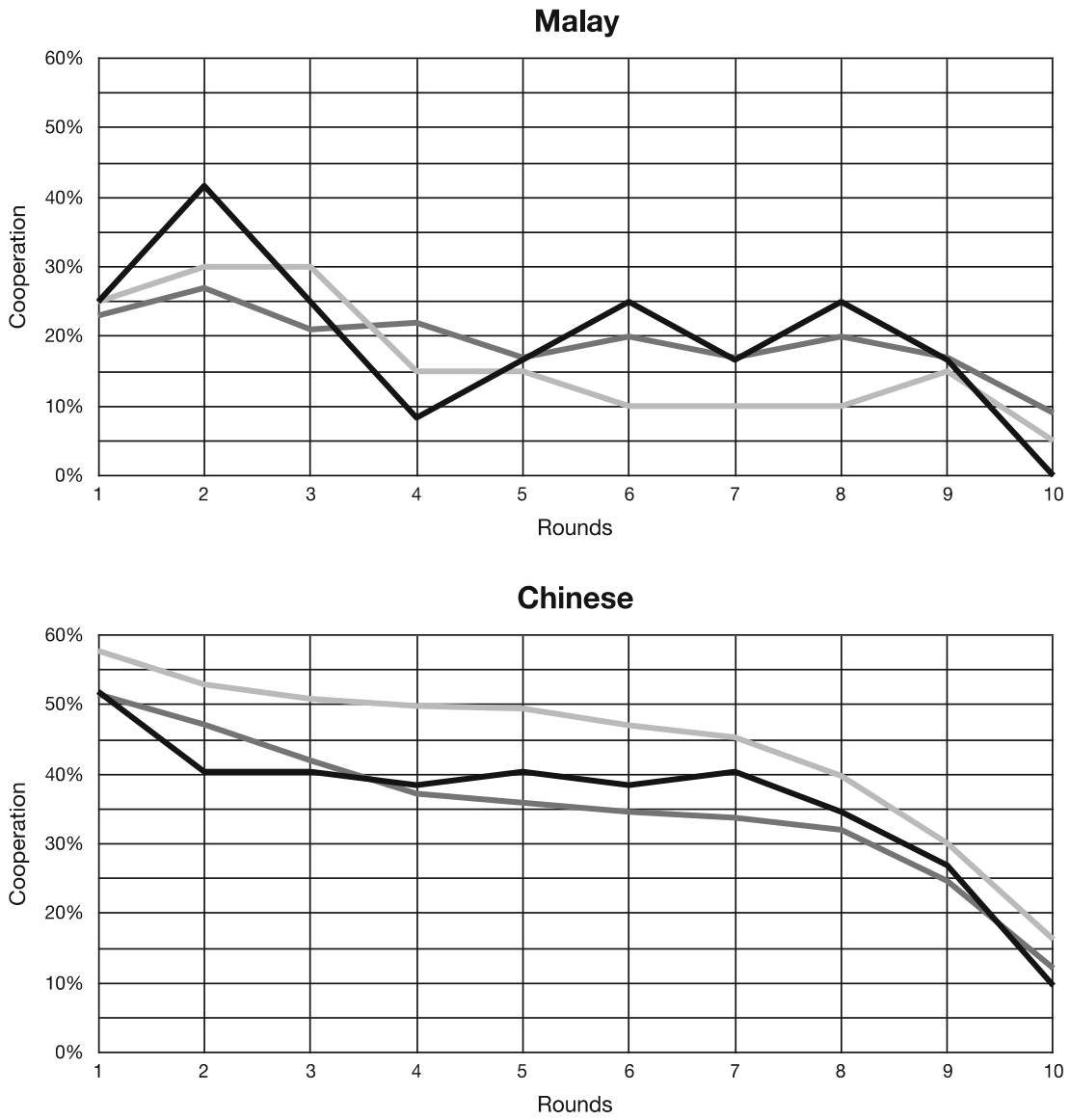

Indian

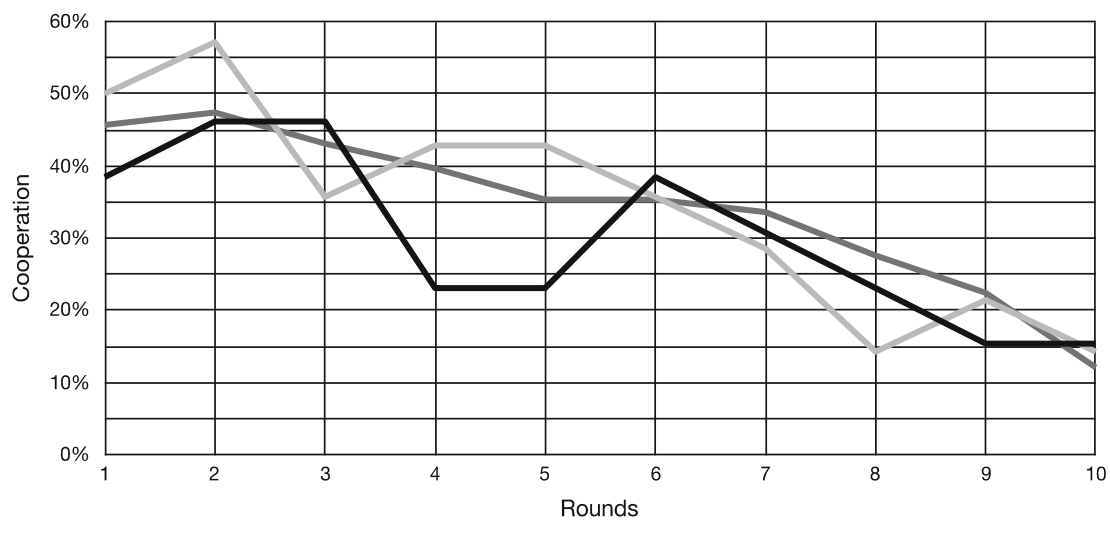

- INFO $=0 \quad-\mathrm{SAME}=1-\mathrm{SAME}=0$

for Malay subjects shows that Chinese Malaysian cooperate more with each other than do Malaysia with other Malays. While the coefficient for Indian subjects is also negative, it is insignificant. This further supports hypothesis $1 \mathrm{~b}$ but only with respect to the 
Table 3 Cooperation (\%) in the first, last and over all rounds by subject ethnic group and experimental condition

\begin{tabular}{|c|c|c|c|c|c|c|c|c|}
\hline \multicolumn{9}{|c|}{ Subject ethnicity } \\
\hline \multicolumn{3}{|c|}{ Chinese } & \multicolumn{3}{|c|}{ Malay } & \multicolumn{3}{|c|}{ Indian } \\
\hline \multicolumn{3}{|c|}{ Round } & \multicolumn{3}{|c|}{ Round } & \multicolumn{3}{|c|}{ Round } \\
\hline All & First & Last & All & First & Last & All & First & Last \\
\hline \multicolumn{9}{|c|}{ All conditions } \\
\hline 39.7 & 54.7 & 14.0 & 19.0 & 23.5 & 7.6 & 33.9 & 45.5 & 12.6 \\
\hline \multicolumn{9}{|c|}{ No information $(I N F O=0)$} \\
\hline 36.2 & 51.9 & 9.6 & 20.0 & 25.0 & 0.0 & 30.0 & 38.5 & 15.4 \\
\hline \multicolumn{9}{|c|}{ Same ethnicity $(I N F O=1, S A M E=1)$} \\
\hline 43.9 & 57.8 & 16.3 & 16.5 & 25.0 & 5.0 & 34.3 & 50.0 & 14.3 \\
\hline \multicolumn{9}{|c|}{ Different ethnicity $(I N F O=1, S A M E=0)$} \\
\hline 35.1 & 51.5 & 12.1 & 19.3 & 23.0 & 9.0 & 34.2 & 45.7 & 12.1 \\
\hline
\end{tabular}

majority Malay community. Models 1 to 4 test for discrimination. In model 1 , the coefficient for MALAY is negative and significant at $1 \%$, but insignificant for INDIAN. This supports the greater general cooperativeness of Chinese subjects, other factors controlled, compared with the majority Malay community but not compared with Indians. Moreover, $\mathrm{INFO} \times \mathrm{SAME}$ is positive and significant at $1 \%$ supporting in-group favouritism over all ethnic groups. INFO is insignificant suggesting that compared to the no information benchmark, subjects do not cooperate less with others of a different ethnicity. Recall that cooperation rates with co-players of unknown and different ethnicity are similar. We also tested whether in-group favouritism holds for all three ethnic groups by estimating the same model for each of them separately (models 2-4). We find that INFO $\times$ SAME is significant for Chinese subjects but not for Malays or Indians supporting the notion of greater in-group favouritism for the former.

Result 1b The Chinese cooperate more with each other than members of other Malaysian ethnic groups.

\section{Discussion}

We presented two quantitative studies conducted in Malaysia to test SOCC hypotheses relating to the values and behaviour of the Overseas Chinese responsible for their economic success. Our findings are summarised in Table 5. The SOCC has three dimensions, the Confucian inheritance, the refugee mentality and economic values. There is no evidence for relatively greater adherence to Confucian values of the Malaysian Chinese compared to Malays or Malaysian Indians, and this is result 1a. In terms of the refugee mentality, the Chinese do not differ in terms of ethnocentrism, trust or opportunism. They do, however, have significantly less confidence in the state compared to both the indigenous Malays and the fellow immigrant Indian community, and this is result 2. In addition, Malaysian Chinese differ from the Malay population in terms of the economic values of work ethic and enterprise, and this is result 3. Finally, our experimental results show greater cooperativeness of the Malaysian Chinese in two ways. First, their intra-ethnic interactions are more cooperative than those within the other ethnic groups. Second, in contrast to the other groups, Chinese Malaysians cooperate relatively more with others who share their ethnicity than with those who do not. This is result $1 \mathrm{~b}$. We now discuss some of the conclusions we draw from our results.

\subsection{Confucianism}

In order to explain economic success, cultural values such as Confucian ones need to systematically vary with it. However, we found no significant differences in Confucian values between the Malaysian ethnic groups despite their very different fortunes. Our result tallies with Lim (2001) who found no differences between Malaysian Chinese and Malays in terms of Hofstede's (1984) cultural dimensions. It may be that Confucianism reflects general Asian rather than 


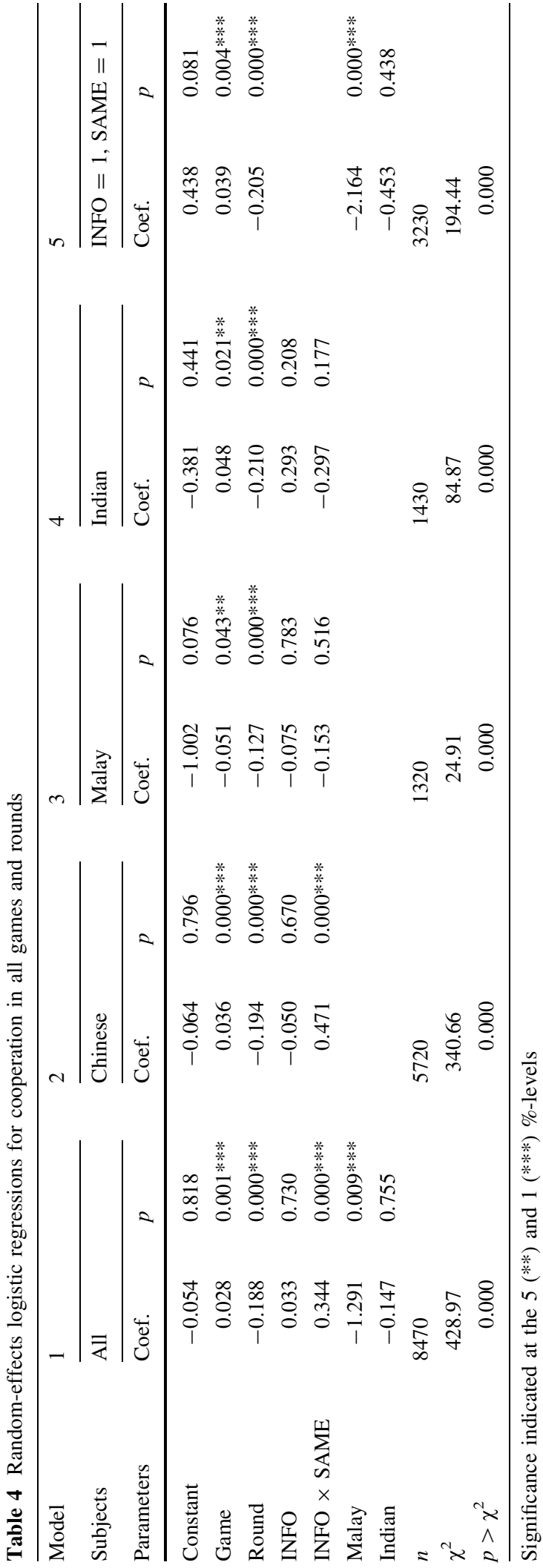

Table 5 SOCC hypotheses and findings

\begin{tabular}{|c|c|c|c|c|c|}
\hline \multicolumn{2}{|c|}{ Hypotheses } & \multicolumn{3}{|c|}{ Difference of $\mathrm{CHI}$ to } & \multirow[t]{2}{*}{ SOCC } \\
\hline No. & Construct & MAL & IND & PRC & \\
\hline \multicolumn{6}{|c|}{ Confucian inheritance } \\
\hline $1 \mathrm{a}$ & Confucian values & 0 & 0 & + & No \\
\hline $1 \mathrm{~b}$ & Cooperation: in-group & + & + & N/A & Yes \\
\hline $1 \mathrm{~b}$ & Cooperation: out-group & - & - & N/A & Yes \\
\hline \multicolumn{6}{|c|}{ Refugee mentality } \\
\hline 2 & Interpersonal trust & 0 & 0 & - & No \\
\hline 2 & Confidence in the state & - & - & - & Yes \\
\hline 2 & Ethnocentrism & 0 & - & 0 & No \\
\hline 2 & Opportunism & 0 & 0 & + & No \\
\hline \multicolumn{6}{|c|}{ Economic values } \\
\hline 3 & Work ethic & + & 0 & + & Yes \\
\hline 3 & Enterprise & + & 0 & 0 & Yes \\
\hline 3 & Progress & 0 & 0 & - & No \\
\hline
\end{tabular}

Differences between Malaysian Chinese (CHI) and Malays (MAL), Malaysian Indians (IND) and Mainland Chinese (PRC) indicated as + for positive significant, - for negative significant and 0 for insignificant

specifically Chinese values (e.g. Storz 1999; Barr 2000, p. 311). Fukuyama (1993) and Weiner (1996) illustrate the problem by asking why the supposedly efficacious Chinese values did not cause economic success in their country of origin. Similarly, "neoConfucian" explanations of the rise of Japan and the East Asian Tiger economies (e.g. Kahn 1979; Reischauer 1974; Pye 1985; Tu 1989; King 1996) fell into disfavour partly because they were used to explain both the economic stagnation and growth of Confucian societies at different times (Fukuyama 1993; King 1996; Wong 1996), leaving these theories prone to unfalsifiability.

Our quantitative analysis based on questionnaire measures was thus unable to support the Confucian hypothesis derived from qualitative work. One explanation may be a disconnect between stated values and behaviour due to social desirability bias (e.g. Fisher 1993). For instance, Fukuyama (1993) criticises Kotkin (1992) on the grounds that he

accepts at face value the oft-repeated assertion of his Chinese interviewees that Confucianism lies at the root of contemporary Chinese success, without explaining why that same Confucianism 
produced economic stasis for the preceding 2500 years (Fukuyama 1993, p. 42).

Chinese respondents in the SOCC studies may have held Confucian values responsible for their success because, as discussed in Sect. 4.1.1, the maintenance of tradition is an important social norm for them (Bond 1988; Wu 1996). This disconnect is illustrated by the new kind of Chinese discussed earlier, where "one observes a present-day high-tech office full of wellqualified and highly efficient operatives of modern office equipment going through a feng-shui ritual to appease the spirits which control the fortune of the location" (Redding 1990, p. 41).

\subsection{Refugee work ethic}

Our results point to two alternative, related explanations. The first is that the Chinese in Malaysia differ particularly in terms of work-related values. Malaysian Chinese self-report a greater belief in hard work and private enterprise than the majority Malays. These two values are conceptually related as the free enterprise system rewards the work ethic relatively more. Accordingly belief in private enterprise and hard work are significantly correlated both for Malaysians in general (Pearson $r=0.143$, $p=0.000)$ and Chinese Malaysians specifically $(r=0.193, p=0.001)$. An ethic of hard work and enterprise may have been heightened when the Diaspora needed to build a new existence abroad (Harrell 1985; Redding 1990, p. 70). We have already seen that enterprise and wealth accumulation came from the values of the Chinese peasantry (Freedman 1979b), but developed in the economic conditions of the diaspora destinations.

A leaning towards the free market system may be related to the greater scepticism that Malaysian Chinese harbour towards their state institutions (Hypothesis 2). Political turmoil in early twentieth century China, ethnic strife in diaspora destinations and later state affirmative action programmes may have taken their tool on Chinese who instead felt a need to rely on their own ingenuity and hard work to survive. In addition, enterprise and hard work may have been a particular characteristic of those Mainland Chinese who took the initiative and risk to emigrate, which they passed on to subsequent generations. The WVS demographic data reveal that among Malaysian
Chinese, those who have at least one immigrant parent have a significantly higher work ethic than those who do not $(p=0.022)$. There are no such differences within the Malays or Indian ethnic groups in Malaysia. In sum, rather than a religious-based (e.g. Protestant or, in this case, Confucian) work ethic, we find evidence for what might be called a refugee work ethic.

\subsection{Intra-ethnic cooperation}

We also find support for a second effect of the refugee experience, a heightened sense of preferential cooperation within the ethnic group. While some commentators dispute the notion of an Overseas Chinese network of cooperation (e.g. Gomez 2007b), we find support at least in the in the underlying behavioural tendency in our experiment. Our experimental results are consistent with the SOCC idea of a cooperative bamboo network based on shared cultural origin, which formed in response to the diaspora experience. Preferential cooperation based on kinship or cultural ties has roots in Confucian thought but may have been accentuated in diaspora conditions when interactions with the indigenous ethnic majority and the state were fraught. Psychological research has shown that minority group membership threatens self-esteem and results in a stronger group identification (Simon and Brown 1987) and greater in-group favouritism (Mullen et al. 1992; Leonardelli and Brewer 2001). According to Henrich and Henrich (2007), an evolutionary process based on group selection turns these tendencies into efficacious social norms in minority immigrant communities:

Ethnic groups, particularly successful minorities, will tend to [...] foster competitive cooperation among coethnics. Groups that fail to do this will tend to vanish via assimilation into larger groups.

Using a mixture of anthropological and psychological research, these authors describe a virtuous cycle of ethnic cooperation within the Chaldean community in Detroit who preferentially interact within their own group due to greater cultural familiarity, which then lubricates these interactions thereby reinforcing group identification as well as preferential interactions within it. The Chaldeans "tend to direct cooperative behaviours and benefits towards members of their own 
ethnic group [...] Chaldean norms have evolved to manage self-interested motives" (p. 163). These norms constitute social capital (e.g. Knack and Keefer 1997) that makes the group economically successful. Similar dynamics may explain the success of the Overseas Chinese in Malaysia and elsewhere.

\subsection{Limitations and further research}

The difference in the economic fortunes of the Overseas Chinese in Southeast Asia and the indigenous communities there is undeniable. Cultural theories such as the ones we examined in this paper claim systematic value and behaviour differences between these groups and offer them as an explanation. However, while significant correlations between culture and economic outcomes are consistent with a causal effect, they alone do not constitute proof (Hoffmann 2013, pp. 2-3). The direction of causality or presence of other factors clouds the issue. Here are three examples.

First, one can argue that Chinese are more entrepreneurial because as migrants they were left with little choice but self-employment. This argument, however, does not explain why migrants of other ethnic groups have been less successful. Moreover, it also complements-rather than substitutes-our explanations in the present-day context: the lesser confidence of Chinese in the state directs them to private enterprise as a path to success, driven by their work ethic and cooperativeness. The dominance of Malays in the public sector and in politics might also negatively influence the trust Chinese put in state institutions, and in turn their greater cooperativeness within bamboo networks as a means to overcome initial socio-economic disadvantages from "Bumiputra" policies that favour the indigenous Malays. The affirmative action policies that give preferences to the Malays in Malaysia in various forms (economic, political etc.) also limit the generalisation of our findings. The "pribumis" in Indonesia or the local Filipinos do not enjoy such preferences. They are also multi-religious (Moslems, Christians and Hindus in Indonesia; Christians and Moslems in the Philippines). Thus, it would be interesting to see if inter-ethnic comparisons in other Southeast Asian countries could produce similar results.
Second, one can argue that economic values such as risk aversion, which influences self-employment and entrepreneurial decisions, are endogenous in that individuals of higher ability are more prone to take such risks (Caliendo et al. 2009). In our case, closeknit business Chinese networks mitigate the strategic downside risks of default and this engenders private enterprise and trade, and vice versa. Our findings of correlation therefore prompt more work on establishing the causal relationships between the distinct Diaspora Chinese cultural features we found in the present study (such as the work values and cooperativeness) and economic success.

Third, the main objective of this paper is to test the validity of each SOCC hypothesis by comparing the strength of these values and behaviours across ethnicities. Thus, our tests exclude interaction effects between predictor variables. As we had discussed, Confucian values could drive cooperation and in turn economic success. This mediating effect is not evident in our results, however. Alternatively, low trust in social institutions might warrant strong interpersonal cooperation, or-in contrast-carry over to weak interpersonal cooperation (Camerer 2003). As discussed above, our results indicate the former. We suggest future research on individual level tests comparing survey and experimental drawn from the same respondents.

In addition, our results have to be interpreted in view of some limiting factors in the research presented here. While the value factors we derive from the WVS are reliable and match the SOCC values well, it would be worthwhile to repeat the exercise with purposedesigned questionnaires designed to elicit values from an Asian perspective generally and a Diaspora Chinese one specifically (see, e.g. Bond et al. 1987). Another issue is the size and nature of the sample in our experiment. While the scope of our experiment is typical for this kind of study given the challenges of experimentation, a replication of our findings with non-student subjects in greater number would be warranted (e.g. Harrison and List 2004). We study the SOCC in the context of Malaysia using data from questionnaire survey and experiment. While this nation is typical for the Chinese Diaspora in Southeast Asia generally, work to replicate our findings in other nations in the region would help ascertain the generality of our results. 
Acknowledgments The authors gratefully acknowledge funding through the British Academy's Committee for SouthEast Asian Studies (Grant Number RL2102).

Open Access This article is distributed under the terms of the Creative Commons Attribution 4.0 International License (http:// creativecommons.org/licenses/by/4.0/), which permits unrestricted use, distribution, and reproduction in any medium, provided you give appropriate credit to the original author(s) and the source, provide a link to the Creative Commons license, and indicate if changes were made.

\section{References}

Ajzen, I. (2012). Attitudes and persuasion (Ch. 15, pp. 367-393). Oxford University Press. doi:10.1093/ oxfordhb/9780195398991.013.0015.

Andreoni, J., \& Miller, J. H. (1993). Rational cooperation in the finitely repeated prisoners' dilemma. Economic Journal, 103, 570-585. doi:10.2307/2234532.

Ariff, M., \& Lim, C. C. (2001). Mobilizing domestic and external resources for economic development: Lessons from the Malaysian experience. Asia-Pacific Development Journal, 8(1), 41-68.

Ariff, M., \& Syarisa Yanti, A. B. (2002). Strenthening entrepreneurship in Malaysia. In Proceedings of the 7th corporate economic briefing (pp. 1-22), Malaysian Institute of Economic Research (MIER).

Audretsch, D. B., Keilbach, M. C., \& Lehmann, E. E. (2006). Entrepreneurship and economic growth. Oxford: Oxford Scholarship Online. doi:10.1093/acprof:oso/97801951835 11.001.0001.

Barr, M. D. (2000). Lee Kuan Yew and the "Asian value" debate. Asian Studies Review, 24(3), 309-334. doi:10. 1080/10357820008713278.

Basu, A. (1998). An exploration of entrepreneurial activity among Asian small businesses in Britain. Small Business Economics, 10, 313-326.

Bertrand, M., \& Mullainathan, S. (2001). Do people mean what they say? Implications for subjective survey data. American Economic Review (Papers and Proceedings), 91(2), 67-72. doi:10.1257/aer.91.2.67.

Bhalla, A., Lampel, J., Henderson, S., \& Watkins, D. (2007). Exploring alternative strategic management paradigms in high-growth ethnic and non-ethnic family firms. Small Business Economics, 32(1), 77-94. doi:10.1007/s11187007-9064-z.

Bhopal, M., \& Rowley, C. (2005). Ethnicity as a management issue: Examples from Malaysia. Asia Pacific Business Review, 11(4), 553-574. doi:10.1080/13602380500135869.

Böhm, D., \& Bergmann, H. (2012). The capability of fundamental values and guãnxi to reduce negative external effects of Chinese agriculture. Food Economics, 9(1-2), 53-65. doi:10.1080/16507541.2012.695146.

Bond, M. H. (1988). Finding universal dimensions of individual variation in multicultural studies of values: The Rokeach and Chinese value surveys. Journal of Personality and
Social Psychology, 55(6), 1009-1015. doi:10.1037/00223514.55.6.1009.

Bond, M. H., Shtin, N. T., et al. (1987). Chinese values and the search for culture-free dimensions of culture. Journal of Cross-Cultural Psychology, 18(2), 143-164. doi:10.1177/ 0022002187018002002.

Bremner, B. (2007). The trouble with Asia's tigers. Business Week, 4056, 122-123.

Caliendo, M., Fossen, F. M., \& Kritikos, A. S. (2009). Risk attitudes of nascent entrepreneurs-new evidence from an experimentally validated survey. Small Business Economics, 32(2), 153-167. doi:10.1007/s11187-007-9078-6.

Camerer, C. (2003). Behavioral game theory: Experiments in strategic interaction. Princeton: Princeton University Press. doi:10.1016/j.joep.2004.06.001.

Chan, S. (2015). The case for diaspora: A temporal approach to the Chinese experience. The Journal of Asian Studies, 74(1), 107-128. doi:10.1017/S0021911814001703.

Chan, A. M., \& Rossiter, J. R. (1998). Construction of a Chineseness values scale and a Chineseness ethnicity scale. In K. Hung \& K. B. Monroe (Eds.), Asia Pacific advances in consumer research (Vol. 3, pp. 61-67). Provo, UT: Association for Consumer Research.

Chandon, P., Morwitz, V. G., \& Reinartz, W. J. (2005). Do intentions really predict behavior? Self-generated validity effects in survey research. Journal of Marketing, 69(2), 1-14. doi:10.1509/jmkg.69.2.1.60755.

Chua, A. (2004). World on fire: How exporting free-market democracy breeds ethnic hatred and global instability. London, UK: Arrow Books. doi:10.1108/0144333081 0890664.

Chuah, S. H., Hoffmann, R., Jones, M. K., \& Williams, G. A. (2009). An economic anatomy of culture: Attitudes and behaviour in inter- and intra-national ultimatum game experiments. Journal of Economic Psychology, 30(5), 732-744. doi:10.1016/j.joep.2009.06.004.

Chuah, S. H., Hoffmann, R., Ramasamy, B., \& Tan, J. H. W. (2014). Religion, ethnicity and cooperation: An experimental study. Journal of Economic Psychology, 45, 33-43. doi:10.1016/j.joep.2014.07.002.

Clark, K., \& Drinkwater, S. (2008). Patterns of ethnic self-employment in time and space: Evidence from British Census microdata. Small Business Economics, 34(3), 323-338.

Constant, A., \& Zimmermann, K. F. (2006). The making of entrepreneurs in Germany: Are native men and immigrants alike? Small Business Economics, 26(3), 279-300.

Cox, T. H., Lobel, S. A., \& McLeod, P. L. (1991). Effects of ethnic group cultural differences on cooperative and competitive behavior on a group task. Academy of Management Journal, 34(4), 827-847. doi:10.2307/256391.

De Clercq, D., Lim, D. S. K., \& Oh, C. H. (2013). Hierarchy and conservatism in the contributions of resources to entrepreneurial activity. Small Business Economics, 42(3), 507-522.

Etzioni, A. (1987). Entrepreneurship, adaptation and legitimization: A macro-behavioral perspective. Journal of Economic Behavior \& Organization, 8, 175-189. doi:10. 1016/0167-2681(87))90002-3.

Fairlie, R. W. (2004). Recent trends in ethnic and racial business ownership. Small Business Economics, 23, 203-218. 
Fang, T., Worm, W., \& Tung, R. L. (2008). Changing success and failure factors in business negotiations with the PRC. International Business Review, 17, 159-169. doi:10.1016/ j.ibusrev.2008.02.012.

Fisher, R. J. (1993). Social desirability bias and the validity of indirect questioning. Journal of Consumer Research, 20(2), 303-315. doi:10.1086/209351.

Fontaine, R., \& Richardson, S. (2003). Cross-cultural research in Malaysia. Cross-cultural Management, 10(2), 75-89. doi:10.1108/13527600310797603.

Frederking, L. C. (2002). Is there an endogenous relationship between culture and economic development? Journal of Economic Behavior \& Organization, 48(2), 105-126. doi:10.1016/S0167-2681(01)00228-1.

Freedman, M. (1979a). The Chinese in Southeast Asia: A longer view. In G. W. Skinner (Ed.), The study of Chinese Society. Stanford, CA: Stanford University Press. doi:10.1017/ s0022463400014089.

Freedman, M. (1979b). The handling of money: A note on the background to the economic sophistication of overseas Chinese. In G. W. Skinner (Ed.), The study of Chinese Society. Stanford, CA: Stanford University Press. doi:10. 2307/2797271.

Fukuyama, F. (1993, April 19). Making it. The New Republic, p. 41.

Fukuyama, F. (1995). Trust: The social virtues and the creation of prosperity. London: Hamish Hamilton.

Godley, M. R. (1981). The Mandarin-capitalists from Nanyang, Overseas Chinese Enterprise in the Modernization of China, 1893-1911. Cambridge, UK: Cambridge University Press. doi:10.1017/CBO9780511529092.

Glaeser, E. L., Laibson, D. I., Scheinkman, J. A., \& Soutter, C. L. (2000). Measuring trust. Quarterly Journal of Economics, 115(3), 811-846.

Gomez, T. (1999). Chinese business in Malaysia: Accumulation, accommodation and ascendance. Routledge: Psychology Press. doi:10.2307/2700366.

Gomez, T. (Ed.). (2003). Chinese Business in South-East Asia: Contesting Cultural Explanations, Researching Entrepreneurship. London, UK: Routledge. doi:10.2307/ 4127270.

Gomez, E. T. (2007a). Family firms, generational change and identity formation: The Chinese in Britain and Malaysia. East Asia: An International Quarterly, 24(2), 153-172. doi:10.1007/s12140-007-9012-1.

Gomez, T. (2007b). Review: Asian godfathers: Money and power in Hong Kong and Southeast Asia. Far Eastern Economic Review, 170(7), 73.

Gomez, E. T. (2012). Targeting horizontal inequalities: Ethnicity, equity, and entrepreneurship in Malaysia. Asian Economic Papers, 11(2), 31-57.

Guiso, L., Sapienza, P., \& Zingales, L. (2006). Does culture affect economic out-comes? Journal of Economic Perspectives, 20(2), 23-48. doi:10.1257/jep.20.2.23.

Guiso, L., Sapienza, P., \& Zingales, L. (2009). Cultural biases in economic exchange. Quarterly Journal of Economics, 124(3), 1095-1131. doi:10.1162/qjec.2009.124.3.1095.

Harianto, F. (1996). Business linkages and Chinese entrepreneurs in Southeast Asia. In W. M. Tu (Ed.), Confucian traditions in East Asian Modernity (pp. 137-153). Cambridge, MA: Harvard University Press.
Harrell, S. (1985). Why do the Chinese work so hard? Reflections on an entrepreneurial ethic. Modern China, 11(2), 203-226. doi:10.1177/009770048501100203.

Harrison, G. W., \& List, J. A. (2004). Field experiments. Journal of Economic Literature, 42(4), 1009-1055. doi:10.1257/ 0022051043004577.

Hemesath, M. (1994). Cooperate or defect? Russian and American students in a prisoner's dilemma. Comparative Economic Studies, 36(1), 83-93. doi:10.1057/ces.1994.6.

Henrich, J., \& Henrich, N. (2007). Why humans cooperate: A cultural and evolutionary explanation. Oxford: Oxford University Press. doi:10.1111/j.1467-9655.2008.00525_ 28.x.

Hoffmann, R. (2013). The experimental economics of religion. Journal of Economic Surveys, 27(5), 813-845. doi:10. 1111/j.1467-6419.2011.00716.x.

Hofstede, G. (1984). Culture's consequences: International differences in work-related values. Newbury Park, CA: Sage Publications. doi:10.1002/job.4030060309.

Hofstede, G., \& Bond, M. H. (1988). The Confucius connection: From cultural roots to economic growth. Organizational Dynamics, 16(4), 5-21. doi:10.1016/0090-2616(88)900095.

Hong, Y. Y., Yang, Y. J., \& Chiu, C. Y. (2010). What is Chinese about Chinese psychology? Who are the Chinese in Chinese psychology? In M. H. Bond (Ed.), The Oxford handbook of Chinese psychology. Oxford, UK: Oxford University Press. doi:10.1093/oxfordhb/9780199541850. 013.0003 .

Huang, Y., Jin, L., \& Qian, Y. (2013). Does ethnicity pay? Review of Economics and Statistics,. doi:10.1162/REST_ a_00281.

Inglehart, R. (1997). Modernization and postmodernization: Cultural, economic, and political change in 43 societies. Princeton: Princeton University Press. doi:10.1017/ S0034670500041371.

Jesudason, J. V. (1997). Chinese business and ethnic equilibrium in Malaysia. Development and Change, 28, 119-141.

Johnson, R. B., \& Onwuegbuzie, A. J. (2004). Mixed methods research: A research paradigm whose time has come. $E d$ ucational Researcher, 33(7), 14-26. doi:10.3102/ 0013189 X033007014.

Julian, C. C., \& Ahmed, Z. U. (2012). Factors impacting international entrepreneurship in Malaysia. Journal of Small Business and Enterprise Development, 19(2), 229-245.

Kahn, H. (1979). World economic development: 1979 and beyond. London, UK: Croom Helm. doi:10.1016/00163287(81)90112-9.

Kao, J. (1993). The worldwide web of Chinese business. Harvard Business Review, 71(2), 24-36. doi:10.1007/s10551006-9140-3.

Khazanah Research Institute (2014). The state of households. http://www.krinstitute.org/

krispublicationStateofHouseholds.aspx. doi:10.1051/ matecconf/20164704002.

King, A. Y. C. (1996). The transformation of Confucianism in the post-Confucian era. In W. M. Tu (Ed.), Confucian traditions in East Asian modernity. Cambridge, MA: Harvard University Press. doi:10.1080/1360311042000 299766. 
Knack, S., \& Keefer, P. (1997). Does social capital have an economic payoff? a cross-country investigation. The Quarterly Journal of Economics, 112(4), 1251-1288. doi:10.1162/003355300555475.

Koning, J., \& Verver, M. (2013). Historicizing the 'ethnic' in ethnic entrepreneurship: The case of ethnic Chinese in Bangkok. Entrepreneurship \& Regional Development, 25(5-6), 325-348. doi:10.1080/08985626.2012.729090.

Koon, H. P. (1997). Robert Kuok and the Chinese business network in Eastern Asia: A study in Sino-capitalism. In T. Brook \& H. V. Luong (Eds.), Culture and economy: The shaping of capitalism in Eastern Asia. Ann Arbor, MI: The University of Michigan Press. doi:10.2307/2658745.

Kotkin, J. (1992). Tribes: How race, religion, and identity determine success in the new global economy. New York: Random House. doi:10.2307/20046842.

Kotkin, J. (2010). The new world order: Tribal ties-race, ethnicity, and religion- are becoming more important than borders. Newsweek, 156(14), 44-47.

Lam, K. C. J. (2003). Confucian business ethics and the economy. Journal of Business Ethics, 43, 153-162. doi:10. 1023/A:1022935820655.

Lee, K. K. (2006). Chinese and Malays in Singapore: Incomes, education and employment, 1954-1995. In: Lian, K. F. (Ed.), Race, ethnicity, and the state in Malaysia and Singapore (p. 47). Leiden: Brill Academic Publishers.

Leonardelli, G. J., \& Brewer, M. B. (2001). Minority and majority discrimination: When and why. Journal of Experimental Social Psychology, 37(6), 468-485.

Lim, L. (2001). Work-related values of Malays and Chinese Malaysians. International Journal of Cross Cultural Management, 1(2), 209-226. doi:10.1006/jesp.2001.1475.

McKeown, A. (1999). Conceptualizing Chinese Diasporas, 1842 to 1949. The Journal of Asian Studies, 58(2), 306-337. doi:10.2307/2659399.

Minai, M. S., Ibrahim, Y., \& Kheng, L. K. (2012). Entrepreneurial network in Malaysia: Are there any differences across ethnic groups? Journal of Business and Policy Research, 7(1), 178-192.

Montesino, M. U. (2012). Cross-cultural conflict and affirmative action: Inter-and intra-ethnic dilemmas of Malaysia's heterogeneous workplace. International Journal of Cross Cultural Management, 12(1), 115-132.

Morris, M. W., Williams, K. Y., Leung, K., Larrick, R., Mendoza, M. T., Bhatnagar, D., et al. (1998). Conflict management style: Accounting for cross-national difference. Journal of International Business Studies, 29(4), 729-748. doi:10.1057/palgrave.jibs.8490050.

Mullen, B., Brown, R., \& Smith, C. (1992). Ingroup bias as a function of salience, relevance, and status: An integration. European Journal of Social Psychology, 22(2), 103-122. doi:10.1002/ejsp.2420220202.

Po, G. Q. (2010). A comparative analysis of the entrepreneurial styles of second, third and fourth generation overseas Chinese and Filipinos in the Philippines. DLSU Business and Economics Review, 19(2), 11-23. doi:10.3860/ber.v19i2.1470.

Powell, B. (1993). Are tribes the key to success? Newsweek, 121(21), 47.

Pye, L. W. (1985). Asian power and politics: the cultural dimensions of authority. Cambridge, MA: Harvard University Press. doi:10.5354/0719-3769.1987.15774.
Rasiah, R. (2002). Government-business coordination and small enterprise performance in the machine tools sector in Malaysia. Small Business Economics, 18(1/3), 177-195.

Rauch, J. E., \& Trindade, V. (2002). Ethnic Chinese networks in international trade. Review of Economics and Statistics, 84, 116-130. doi:10.1162/003465302317331955.

Redding, S. G. (1990). The spirit of Chinese capitalism. Boston, MA: Walter de Gruyter \& Co. doi:10.1177/ 017084069201300214.

Redding, G. (1995). Overseas Chinese networks: Understanding the enigma. Long Range Planning, 28(1), 61-69. doi:10. 1016/0024-6301(94)00071-C.

Redding, S. G. (1996). Societal transformation and the contribution of authority relations and cooperation norms in Overseas Chinese business. In W. M. Tu (Ed.), Confucian traditions in East Asian modernity. Cambridge, MA: Harvard University Press.

Redding, S. G., \& Witt, M. A. (2008). The future of Chinese capitalism. Oxford, UK: Oxford University Press. doi:10. 1093/acprof:oso/9780199575879.001.0001.

Reischauer, E. O. (1974). The Sinic world in perspective. Foreign Affairs, 52(2), 341-348. doi:10.2307/20038053.

Robson, M. C. (2007). Explaining cross-national variations in entrepreneurship: The role of social protection and political culture. Comparative Labor Law and Policy Journal, 28(4), 863-892.

Schwartz, S. H. (2001). Value hierarchies across cultures: Taking a similarities perspective. Journal of Cross-Cultural Psychology, 32(3), 268-290. doi:10.1177/ 0022022101032003002.

Shafii, Z., Abiddin, N. Z., \& Ahmad, A. R. (2009). Ethnic heterogeneity in the Malaysian economy: A special reference to the ethnic group participation in financial planning activities. The Journal of International Social Research, 2(8), 394-401.

Simon, B., \& Brown, R. (1987). Perceived intragroup homogeneity in minority- majority contexts. Perceived intragroup homogeneity in minority-majority contexts. Journal of Personality and Social Psychology, 53(4), 703-711. doi:10.1037/0022-3514.53.4.703.

Sowell, T. (1996). Migrations and cultures: A world view. New York, NY: Basic Books. doi:10.1007/BF03355976.

Stapleton, K. (1997). The bamboo network: How expatriate Chinese entrepreneurs are creating a new economic superpower in Asia. The China Business Review, 2, 54.

Storz, M. L. (1999). Malay and Chinese values underlying the Malaysian business culture. International Journal of Intercultural Relations, 23(1), 117-131. doi:10.1016/ S0147-1767(98)00028-5.

Studwell, J. (2007). Asian godfathers: Money and power in Hong Kong and Southeast Asia. New York: Grove Press. doi:10.1111/j.1467-8411.2008.00213_7.x.

Suddle, K., Beugelsdijk, S., \& Wennekers, S. (2010). Entrepreneurial culture and its effect on the rate of nascent entrepreneurship. Entrepreneurship and culture (pp. 227-244). Heidelberg: Springer. doi:10.1007/978-3-54087910-7_11.

Tanzer, A. (July 18, 1994). The bamboo network. Forbes.

Tong, S. Y. (2005). Ethnic networks in FDI and the impact of institutional development. Review of Development Economics, 9(4), 563-580. doi:10.1111/j.1467-9361.2005.00294.x. 
Triandis, H. C. (1989). Cross-cultural studies of individualismcollectivism. In J. J. Berman (Ed.), Nebraska symposium on motivation: Cross-cultural perspectives (Vol. 37, pp. 41-131). Lincoln: University of Nebraska Press.

Tu, W. M. (1989). The rise of industrial East Asia: The role of Confucian values. The Copenhagen Journal of Asian Studies, 4, 81-97.

Tung, R. L., \& Baumann, C. (2009). Comparing the attitudes toward money, material possessions and savings of overseas Chinese vis-à-vis Chinese in China: convergence, divergence or cross-vergence, vis-à-vis 'one size fits all' human resource management policies and practices. The International Journal of Human Resource Management, 20(11), 2382-2401. doi:10.1080/09585190903239724.

Uhlaner, L., \& Thurik, R. (2007). Postmaterialism influencing total entrepreneurial activity across nations. Journal of Evolutionary Economics, 17, 161-185. doi:10.1007/ s00191-006-0046-0.

Verkuyten, M., \& Khan, A. (2012). Interethnic relations in Malaysia: Group identifications, indispensability and inclusive nationhood. Asian Journal of Social Psychology, 15(2), 132-139. doi:10.1111/j.1467-839X.2012.01374.x.

Wah, S. S. (2001). Chinese cultural values and their implication to Chinese management. Singapore Management Review, $23,75-83$.

Wang, G. (1991). Among non-Chinese. Daedalaus, 120(2), 135-157.

Wang, Q. F., \& Liu, C. Y. (2014). Transnational activities of immigrant-owned firms and their performances in the USA. Small Business Economics, 44(2), 345-359.

Weber, M. (1976). The Protestant Ethnic and the Spirit of Capitalism. London: Allen \& Unwin.

Weidenbaum, M., \& Hughes, S. (1996). The bamboo network: How expatriate Chinese entrepreneurs are creating a new economic superpower in Asia. New York, NY: The Free Press. doi:10.5860/CHOICE.34-0420.

Weiner, M. (1996). Nations without borders: The gifts of folk gone abroad. Foreign Affairs, 75(2), 128-134. doi:10. 2307/20047493.
Wennekers, S., Thurik, R., van Stel, A., \& Noorderhaven, N. (2007). Uncertainty avoidance and the rate of business ownership across 21 OECD countries, 1976-2004. Journal of Evolutionary Economics, 17(2), 133-160. doi:10.1007/ s00191-006-0045-1.

Westwood, R. (1997). Harmony and patriarchy: The cultural basis for 'paternalistic headship' among the overseas Chinese. Organization Studies, 18(3), 445-480. doi:10. 1177/017084069701800305.

Williamson, O. E. (1985). The economic institutions of capitalism. New York, NY: The Free Press.

Wong, J. (1996). Promoting confucianism for socioeconomic development. In W. M. Tu (Ed.), Confucian traditions in East Asian Modernity. Cambridge, MA: Harvard University Press.

World Values Survey (2013). http://www.worldvaluessurvey. org

Wu, D. Y. H. (1996). Chinese childhood socialization. In M. H. Bond (Ed.), The Handbook of Chinese psychology (pp. 143-154). Oxford, UK: Oxford University Press. doi:10. 1093/oxfordhb/9780199541850.001.0001.

Wyrwich, M. (2015). Entrepreneurship and the intergenerational transmission of values. Small Business Economics, 45(1), 191-213. doi:10.1007/s11187-015-9649-x.

Xavier, S. R., Ismail, A. Z., \& Ahmad, S. Z. (2010). Cultural and economic determinants of entrepreneurial propensity: A study of multi-ethnic society in Malaysia. Journal of Asia Entrepreneurship and Sustainability, 6(2), 67-83.

Yin, L. C. (2003). Do traditional values still exist in modern Chinese societies? Asia Europe Journal, 1, 43-59. doi:10. 1007/s103080200001.

Zak, P. J., \& Knack, S. (2001). Trust and growth. The Economic Journal, 111(470), 295-321.

Zelekha, Y., Avnimelech, G., \& Sharabi, E. (2013). Religious institutions and entrepreneurship. Small Business Economics, 42(4), 747-767. doi:10.1007/s11187-013-9496-6. 